\title{
A THEORETICAL FRAMEWORK FOR PSYCHIATRIC REHABILITATION
}

\author{
L R Uys
}

\begin{abstract}
A Theoretrical framework for psychiatric rehabilitation is presented It is based on four existing models in the field and describes the process of relapse, intervening variables, interventions and outcomes. Some interactions between the elements of he framework are given and the research support and inpllcations for nursing are eaddressed briefly.
\end{abstract}

\section{Opsomming}

in Teoretiese raamwerk vir psigiatriese rehabilitasie word gegee. Dit is gebaseer op vier bestaande modelle in die veld en beskryf die proses van terugval, tussenveranderlikes, tussentredes en gevolge. Enkele interaksies tussen die elemente van die raamwerk word gegee en die navorsing wat die raamwerk onderskeun sowel as die implikasies vir verpleging work kortliks aangespreek.

\section{INTRODUCTION}

Psychiatric services have developed dramatically during the last century.

During the latter half of the 19th century and the first part of the 20th century, services were embedded firmly in the custodial era and large asvlums were established in which doctors and es tried to keep patients quiet and safe. Early in the present century social scientists became interested in these institutions and their research showed that such environments were not neutral or benign, but increased the morbidity of the patients (Barton, 1976). Consumer groups were established and pressurized asylum authorities to re-assess their institutions (Beers, 1907) eventually leading to the therapeutic environment era, during which there was focus on making inpatient settings more therapeutic through physical changes and social interventions.

In the 1940's the next great development came, made possible by the advent of neuroleptics, which consisted of moving patients out of the institutions in vast numbers - the deinstitutionalization/community mental health era. The action in psychiatric care was suddenly in the community and not in hospitals, because most of the patients were in the community. In South Africa deinstitutionalization was not carried out abruptly as in North America, but nevcrtheless the shift was substantial and at the moment we are on the brink of the next phase, the rehabilitation era (Anthony, Cohen and
Farkas, 1990). Just as it suddenly was realized that institutions were not necessarily therapeutic, we now realize that simply moving the patient into the community does not necessarily increase the quality of life or level of health. Community treatment needs to be

TABLE 1

Traditionally perceived differences between Rehabilitation and Treatment

\begin{tabular}{|c|c|c|}
\hline & AEHABILITATION & TREATMENT \\
\hline MISSION & $\begin{array}{l}\text { Improved functioning and } \\
\text { satisfaction in specific } \\
\text { environments }\end{array}$ & $\begin{array}{l}\text { "Cure', symptom reduction, or } \\
\text { the development of } \\
\text { therapeutic insights }\end{array}$ \\
\hline $\begin{array}{l}\text { UNDERLYING CAUSAL } \\
\text { THEORY }\end{array}$ & No causal theory & $\begin{array}{l}\text { Based on a variety of causal } \\
\text { theories that determine the } \\
\text { nature of the intervention }\end{array}$ \\
\hline Focus & Present and future & Past, present and future \\
\hline DIAGNOSTIC CONTENT & $\begin{array}{l}\text { Assess present and needed } \\
\text { skills and supports }\end{array}$ & $\begin{array}{l}\text { Assess symptoms and } \\
\text { possible causes }\end{array}$ \\
\hline PRIMARY TECHNIQUES & $\begin{array}{l}\text { Skills teaching, skills } \\
\text { programming, resource } \\
\text { co-ordination, resource } \\
\text { modification }\end{array}$ & Psychotherapy, chemotherapy \\
\hline HISTORICAL ROOTS & $\begin{array}{l}\text { Human resource } \\
\text { development; vocational } \\
\text { rehabilitation; physical } \\
\text { rehabilitation; client-centred } \\
\text { therapy; special education } \\
\text { and learning approches }\end{array}$ & $\begin{array}{l}\text { Psychodynamic Theory; } \\
\text { physical medicine }\end{array}$ \\
\hline
\end{tabular}

therapeutic: it should rehabilitate the patient to the highest possible level of functioning.

In the South African context, the community psychiatric services are mosily still in the deinstitutional era. The paradigm shift to rehabilitation has not yet happened, as illustrated by contrasting what Anthony, Cohen and Farkas (1990) descibe as the "treatment" approach with the rehabilitation approach (Table 1).

Most of the community psychiatric service in South Africa is in the hands of nurses. This might not be true for urban pockets of White or Asian patients, but for the largest group in the country, the Black patients, this is undoubtedly true. And since the rehabilitation era is upon us, psychiatric nurse researchers might find it useful to have a theoretical framework for research in this area.

\section{AVAILABLE THEORETICAL FRAMEWORKS}

The framework presented in this article has been based mainly on the rehabilitation model proposed by Anthony et al (1990), the vulnerability, stress, coping and competence 
model of mental disorders by Anthony and Liberman (1986), the stress-diathesis model of schizophrenia by Falloon, Boyd and McGill (1984) and the interactive model of schizophrenia proposed by Liberman et al (in Bellack, 1984). It is not really a new model, but an effort to bring together these existing models in an accessible way.

Anthony et al (1990) fits psychiatric rehabilitation into the general framework of rehabilitation as formulated by the World Health Organization (1978) by distinguishing between impairment, disability and handicap.

Anderson and Liberman (1986) present a model representative of a large portion of the psychiatric rehabilitation establishment and focus on the role of specific psychosocial interventions in developing personal and familial coping skills, as well as interpersonal and vocational competence, which is seen collectively as protective factors in the course of mental illness. This model seems to include most major concepts, but it needs more elaboration for research purposes, as relationships between concepts are not made explicit in researchable terms.

Falloon et al (1984) describe the relationship between stress, coping mechanisms, neuroleptic medication and relapse in schizophrenic patients. The diathesis (environmental) part of the model refers to the effect of stress in the environment. If this is high, even a relatively minor stressor may cause relapse, while if the environmental stress is low, a more substantial event would be needed to cause relapse. In this model the environmental stress is seen as strongly related to the emotional climate in the family. Since stress is experienced in an extremely individual way, this model may be difficult to operationalize.

Liberman et al (1984) outline the interaction between biological, behavioural and environmental factors in the symptom formation of schizophrenics. This is then linked to enduring vulnerability characteristics, transient states and outcomes. Although this model is very comprehensive, it does not distinguish adequately between the factors in the social network and those in the more general environment, so that possible interventions become confused.

Two of these models are specifically about schizophrenia, but this can be generalized to all psychiatric rehabilitation on the basis of the numerous findings showing that traditional psychiatric diagnoses are irrelevant to the process of rehabilitation (Anthony and Nemec in Bellack, 1984), and the fact that most long-term psychiatric patients in any case suffer from schizophrenia.

None of these models seem to include all the main variables in this field or make the relationships sufficiently clear.

\section{COMPONENTS:}

\section{Assumptions}

This framework is based on the assumption that patients and their families are active members of the psychiatric team, and that they should have at their disposal up-to-date information presented in an understandable and non-threatening way about the condition and its treatment.

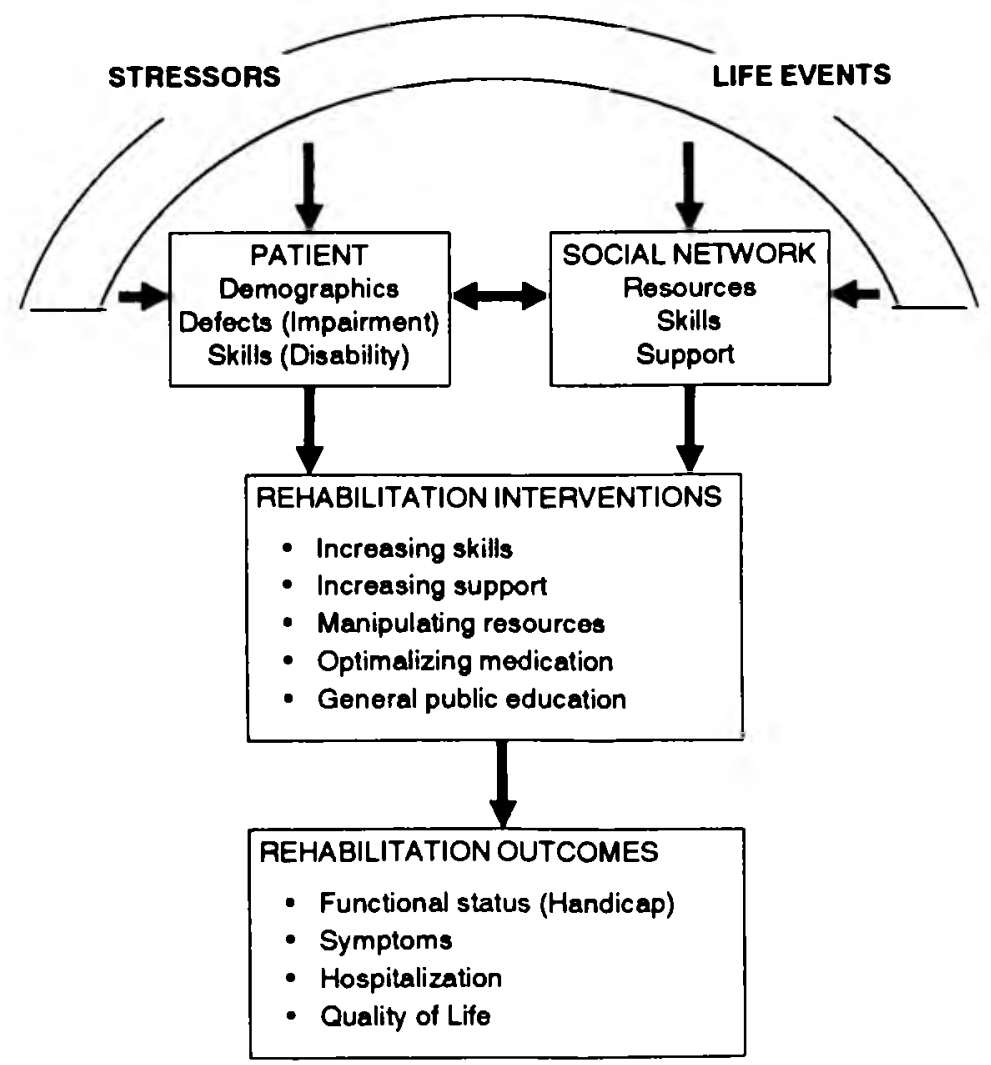

FIGURE 1

Psychlatric Rehabilitation
It is further based on the assuption that mental illness is usually a long-term condition, which can be managed successfully mainly in the community if the rehabilitation approach rather than the treatment approach is used, and if adequate resources are available in the community.

It further assumes that rehabilitation starts after diagnosis and is the same as tertiary prevention.

\section{Process of Relapse}

This framework describes the process of relapse as consisting of four steps:

1. A life event is seen as stressful by the patient, who sees a discrepancy between his/her resources and the demands of the situation

2. The stress leads to an increase in the symptoms of the underlying psychiatric condition, such as an increase in hallucinations, and/or an increase in non-specific symptoms associated with stress, such as sleep disturbances, mu tension, etc.

3. The intervening variables determine how much stress the patient can absorb before relapse. If the stress passes this critical point, the patient will relapse, which means that an acute episode of the psychiatric condition is experienced, perhaps necessitating rehospitalization.

\section{Intervening Variables}

The intervening variables include individual, and social network factors (see Figures 1 and 2).

\section{Individual factors:}

Demographic factors such as age and gender have been shown by research to influence rehabilitation outcomes. The mechanisms of these processes are not clear.

The impairment of the patient refers to the actual loss or abnormality in psychological physiological or anatomical structure function.

Impairment may be greater or smaller, and is affected by the adequacy of the medication (for a full discussion of the interventions mentioned in this section, see next section "interventions") For example the actual changes in neuro-transmission during schizophrenia are seen as the impairment of the schizophrenic.

The disability of the patient refers to any restriction of ability to perform an activity in the way and within the range considered normal for that age and culture. Again using the example of the schizophrenic patient, the lack of motivation and concentration in the patient caused directly by the impairment, would be the disability. It refers mainly to deficiencies in the following skills:

* Coping skills which are the skills by which a person attempts to alleviate, attenuate or remove stress or threat (Garland and Bush, 1982). This includes a large array of covert and overt bchaviours.

* Social skills which are skills a person uses to interact with others in a way which is 


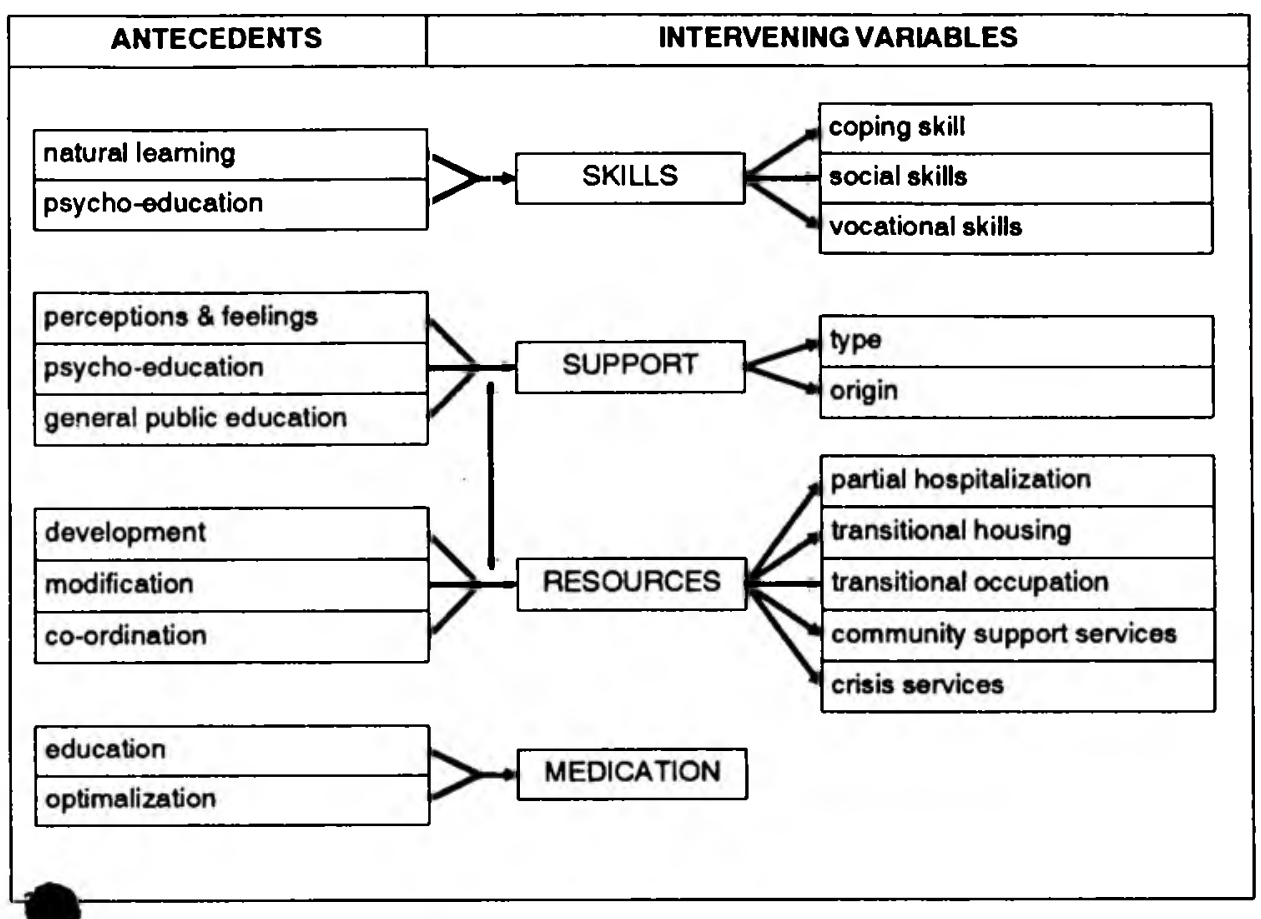

FIGURE 2

Intervening Variables and their Antecedents

situationally appropriate and it includes being able to perceive the parameters of the interactions (interpreting), communicating and listening (Morrison and Bellack in Bellack, 1984).

* Vocational skills which are the skills necessary in the workplace for obtaining, keeping and changing jobs.

Skills deficits are a hallmark of most long-term psychiatric patients and the treatment approach of choice is psycho-education. This is bascd on the behavioural model, which sees these not as innate abilities that one has or does not have, but as skills that can be learnt.

\section{Social network factors:}

I - ocial network of a patient includes all those people, groups and institutions with whom he/she is socially connected (Gottlieb, 1981). It is from this social network that the social support of a patient is derived.

* Social support can be described in terms of the source of the support (who gives it), or in terms of the type of suppon. Three types of social support have been identified by Khan and Antonucci (in Funch, Marshall and Gebhardt, 1986):

affect - expressions of liking or respect; affirmation - expressions of agreement or endorsement of some act or statement; aid-transactions involving direct assistance.

Social support can be increased by psycho-education, resource manipulation and general public education.

* Skills: Just as in the case of the individual patient, the people in the social network need the necessary skill to deal with the problems created by the illness of the patient. Social skills and coping skills are the main focus here.

Social skills of families include healthy communication patterns. Coping skills include handling both the treatment and the disability of the patient. The treatment approach for skill development is again the psycho-educational process.

\section{Interventions}

The main interventions used in rehabilitation have been mentioned already in the discussion of intervening variables, and will be defined briefly.

Psycho-education is the teaching of knowledge and skills that will enhance the psycho-social functioning of the trainee. It can be either individual or small group teaching, and makes use of a variety of methods. It includes skills training which is based largely on the behaviural model.

Medication refers to psycho-active medication used in the treatment of psychiatric patients and are mainly neurolcptics, antidepressants, anti-parkinsonian drugs and anti-mania drugs. Education of the patient and carers about the medication and its use is essential for them to ensure optimal use. Optimalization of the medication refers to a medication regime that fits the patient best and is responsive to changes in the patient's condition.

Resource manipulation implies all actions aimed at making available to the patient and his/her family the appropriate resources in the community. A resource may be ascrvice setting, a programme within such a setting, a person who can act as a resource, financial assistance schemes or any other entity which could assist the patient or the family.

\section{Resource manipulation includes:}

* resource coordination, which may be matching the patient to the resource, or creatively combining different resources to suit the needs of a particular patient;

* resource modification, which includes proposing change in a resource to make it more accessible or effective, training people inside such a resource for the change, and offering a consultation service to such a setting;

- resource development, when no appropriate resources are available, and it may be necessary to get an interested group together, plan for the establishment of the resource, and implement the plan.

General public education refers to mass health education to promote understanding of the psychiatric conditions, the psychiatric patient and the role of the community, and decrease of stigmatization of patients and their families.

\section{Outcomes}

Ilandicap refers to the disadvantage of a person that limits or prevents the fulfillment of a role that is normal for him/her according to age and culture. The handicap may be related to the disability of the patient, but it may also be influenced by the restrictions caused by the community. The most common outcome measurements used in rehabilitation studies are:

\section{* Functional status:}

The functional status of a person describes the skills and abilities to perform the activities of daily living, vocational pursuits, social interactions, leisure activities and other required behaviour (Granger and Gresham, 1984). It is linked very closely to the concept of handicap, as shown by Granger in his 1984 analysis.

In his summary of available measures of functional status of psychiatric patients, Wallace (1984) mentions a variety of available scales. The one that scems most appropriate to the South African outpatient population, is the Life Skills Profile (Rosen, Hadzi-Paclovic and Parker, 1989), since it relatively short and simple, and does not depend on professional observation in situ.

\section{* Symptoms:}

The overall status of the psychiatric symptoms of the patient is a good indicator of health status, especially in terms of impairment and disability.

Lukoff, Liberman and Nuechterlein (1986) summarized measuring tools for the symptomatology of schizophrenics and list a large number. For patients with depression the Ilamilton Scale is probably the best known (Hamilton, 1960).

\section{* Hosnitalization record:}

The frequency and duration of the hospitalization of the patient is an outcome of social and cconomic importance. 


\section{Quality of life:}

The general satisfaction with life of both the patient and the family, is an outcome which as not been given much direct attention. Studies of the problems of families has thrown light on this aspect, but direct measures are scarce.

\section{INTERACTIONS}

Since the elements of the framework have now been described, the interactions between these elements may be explored.

\section{Decreasing the perception of stress}

1. The more positive the patient's perception of his/her own coping skills, the fewer life events will be seen as stressful.

2. The more social support the patient is given, the fewer life events will be seen as stressful.

3. The better the patient's social and vocational skills, the fewer life events will be seen as stressful.

4. The better the understanding, coping skills and communication skills of the patient and the family, the less the environmental stress.

5. The better the understanding of the public at large, the less the envrionmental stress.

\section{Decreasing the results of stress}

6. The better the patient's coping and social skills, the less general and specific symptoms will be caused by an increase in stress.

7. The better the social support, the less general and specific symptoms will be caused by an increase in stress.

8. The better the communication in the family, the less the symptoms will be caused by an increase in stress.

9. The better the coping skills of the social network, especially those of the family, the less symptoms will be caused by an increase in stress.

10. The belter the coping skills of the patient, the better will be the ability to monitor symptoms and prevent relapse.

11. The better the medication regime, the less will be the chances of relapse.

12. The better the skill of the family to cope with increased symptoms, the less the chances of relapse.

These are by no means an exhaustive list of the relationship statements that are inherent in the framework, but, it focuses on the main relationships that have some research data to support them.

\section{RESEARCII SUPPORT FOR TIIE FRAMEWORK}

There is widespread support for the idea that stressfull events play a precipitating role in mental illness (Kaplan and Sadock, 1988). In the case of schizophrenia, a study by Leff et al (1973) linked the rchospitalization of patients to a stressful event in the previous 5 weeks. This linkage is also recognized in prevailing crisis intervention models (Hoff, 1984), which are used in the treatment of many forms of emotional distress. Further support for this contention is quoted by Falloon et al (1984) in discussion of the stress-diathesis model.

The contention that an increase in family skills and support influences the rehabilitation process, also is documented widely. The firs movement in this direction came from the firs generation of family therapists, such as Bowen with his focus on differentiating patients from the family ego mass (Guerin, 1976). The mos influential studies, however, havebeen the studies of Brown, et al (in Leff and Vaughn 1985) about what they termed "expressed emotion" - EE. They found that schizophrenic patients whose families were over-involved and critical of the schizophrenic member, or hostile and under-involved (High EE families) were rehospitalized significantly more than those from low EE families. Many programmes to improve family coping and support have been lested and found to be very successful (Hogarty et al, 1986; Strachan, 1986; Goldstein in Bellack, 1984).

Skills training as a major treatment modality for psychiatric patients was developed by behavioural therapists. In their work they have shown that psychiatric patients have important social skill deficits, that they can be taught these skills, and that they will use these skills in homework as part of the total teaching programme (Morrison and Bellack, in Bellack 1984; Hierholzer and Liberman, 1986; Goldman and Quinn, 1988). Morrison and Bellack (in Bellack, 1984) caution, however, that the effect of these specific skills on the general functional status of the patients is not yet clear.

The effect of different kinds of transitional services on rehabilitation outcomes has been addressed by numerous authors (Bellack, 1984; Castaneda and Sommer, 1986; Dickey et al, 1986; Faulkner et al, 1986). However, Anthony et al (1990) focus attention on the need to fit the needs of the patient to the available resources, and to manipulate the resources to promote a better fit if necessary. They include resource assessment, planning, coordination and modification as major parts of the rehabilitation process. Mechanic (1986) makes the statement that deinstitutionalization of patients without the deinstitutionalization of resources is the main cause of the revolving door syndrome.

\section{IMPLICATIONS FOR NURSING}

This framework could serve to direct:

- the documentation by nurses of data about psychiatric outpatients;

* the interventions employed by community psychiatric nurses:

- the research in this area.

Documentation about psychiatric outpatients

The current documantation about psychiatric outpatients is stercotyped and limited. It usually concerns only data about medication use and side-effects, which is in line with the treatment approach that is being followed in these services.

If the rehabilitation approach is implemented, data about the coping skills and social skills will be necessary, as well as details about social support and the knowledge and skill of the family. Furthermore, aspects such as life events, stress levels and symptom monitoring will be included.

Such documents could not fail to support improved planning and case management.

Interventions employed by psychiatric nurses

The framework clarifies the interventions needed in a comprehensive rehabilitation programme and significantly broadens the scope of nurses. This does not refer only to psychiatric nurses in the community services, but also to those in in patient settings, since rehabilitation starts immediately after diagnosis and periods of hospitalization are not excluded from this process.

The strategies of psycho-education and rese development seem to need particular attenron from South African psychiatric nurses, since these aspects show severe short-comings

\section{Research into psychiatric rehabilitation}

Although this framework is based on much research over the last $\mathbf{4 0}$ years, there are many questions still unanswered, and much research has never been replicated. Neither have we had many projects in South Africa which can throw light on the applicability to local heal th service systems.

There is therefore a need for psychiatric nurse researchers to investigate almost every aspect of this framework in our context. Working with a common framework will allow projects to build onto each other and amend and develop the framework systematically.

\section{CONCLUSION}

Because of their unique place in psychiatric services in South Africa, n. es can play a very exciting role during the rehabilitaion era of psychiatric services. For the majority of psychiatric patients in this country the psychiatric nurse is the major contact. This role may shift in future to community health nurses if psychiatric care becomes part of general primary health care services. Whatever happens, we must make sure that nurses play the role thcy deserve and that they do this with the expanded perspective of the rehabilitation era, and not the narrow perspective of the treatment cra.

When the change from the custodial to the therapeutic era look place the nurse was also in an excellent position to play a major role. But in that era nurses were very definitely followers and not leaders. This was probably due to their academic under-preparedness at that stage, when they were over-run by eager young university graduates in the other disciplines.

Psychiatric nurses in South Africa are now much better prepared academically and should be able to make this development their forte. 


\section{BIBLIOGRAPIIY}

ANTHONY W, COHEN M, FARKAS, $M$. Psychiatric Rehabilitation. Boston: Boston University, 1990.

ANTHONY W, LIBERMAN R P The practice of psychiatric rehabilitation. Schizophrenia Bulletin 1986; 12(4): 542-559.

BARTON R. Institutional Neurosis. 3rd ed. Bristol: John Wright \& Sons, 1971.

BEERS C. A mind that found itself. Non-cited publisher, 1907.

BELLACK AS, editor. Schizophrenia: treatment, management and rehabilitation. Orlando: Grune and Stratton, 1984.

CASTANADA D, SOMMER R. Patient housing options as viewed by parents of the mentally ill. Hospital and Community Psychiatry 1986; 37(12): 1238-1242.

CUkRAN JP, Monti PM, editors . Social skills training. New York: The Guilford Press, 1982.

DICKEY B et al. The Quarterway House: a two-year cost study of on experimental residential program. Hospital and Community Psychiatry 1986; 37(11) 1136-1143.

FALLOON JRH, BOYD JL, MOGILL CW. Family care of Schizophrenia. New York: Guilford Press, 1984.

FAULKNER LR et al. Small group work therapy for the mentally ill. Hospital and Community Psychiatry 1986; 37(3) 273-279.
FUNCI DP, MARSHALL JR, GEBHARDT GP. Assessment of a short scale to measure social support. Social Science in Medicine 1986; 23(3): 337-344.

GARLAND LM, BUSH CT. Coping behaviours and nursing. Reston: Reston Publ. Co. 1982.

GOLDMAN CR, QUINN FL. Effects of a patient education program in the treatment of schizophrenia. Hospital and Community Psychiatry 1988, 39(3): 282-286.

GOTTLIED BH, editor. Social networks and social support. Sage Studies in Community MentalHealth, Vol 4. Beverley Hills: Sage Publ. 1981.

GRANGER CV, GRESHAM GE, editor. Functional Assessment in rehabilitation medicine. Baltimore: Williams and Wilkins, 1984.

GUERIN PJ, editor. Family therapy, New York: Gardner Press, 1976.

HAMILTON M. A rating scale for depression. Journal of Neurology, Neurosurgery and Psychiatry 1960; 23: 56-62.

HIERHOLZER RW, LIBERMAN RP. Successful living: a social skill and problem - solving group for the chronic mentally ill. Hospital and Community Psychiarry 1986; 37(9): 913-918

HOFF LA. People in crisis. 2nd ed. Menlo Park: Addison - Wesley, 1984.

KAPLAN HI, SADOCK BJ. Synopsis of Psychiatry. 5th ed. Baltimore: Williams and Wilkens, 1988.
LEFF J, VAUGHN C. Expressed emotion in Families. New York: Guilford Press, 1985.

LUKOFF D, LIBERMAN RP, NUECHTERLEIN KH. Symptom monitoring in the rehabilitation of psychiatric patients. Schizophrenia Bulletin 1986; 12(4): 678-697.

MECHANIC D. The challenge of chronic mental illness: a retrospective and prospective view. Hospital and Community Psychiatry 1986; 37(9): 891-896.

ROSEN A, HADZJ-PAVLOVICD, PARKER D. The Life Skills Profile: A measure assessing function and disability in schizophrenia. Schizophrenia Bulletin 1989; 12(4): 604-624.

STRACHAN AM. Family intervention for the rehabilitation of schizophrenia: toward protection and Coping. Schizophrenia Bulletin 1986; 12(4): 678-697.

WALLACE CJ. Functional assessment in rehabilitation. Schizophrenia Bulletin 1986; 12(4): 604-624.

World Health Organization. Disability prevention and rehabilitation. International Journal of Rehabilitation Research 1878; 1(4).

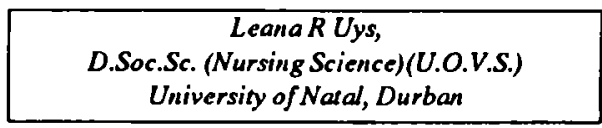

